\title{
Synthesis and Characterization of Fly Ash Geopolymer for Water Absorbent Material
}

\author{
Ufafa Anggarini ${ }^{1, *}$, Ndaru Candra Sukmana $^{2}$, and Fandi Angga Prasetya $^{1}$ \\ ${ }^{1}$ Departement of Chemical Engineering, Universitas Internasional Semen Indonesia, Indonesia \\ ${ }^{2}$ Departement of Engineering Management, Universitas Internasional Semen Indonesia, Indonesia
}

\begin{abstract}
Geopolymer as a water absorbent material has been synthesized from fly ash. This research aims to determine the ability of geopolymer to save water content with variations of $\mathrm{NaOH}$ molar ratio. In this research, the synthesis of geopolymer was conducted by setting $\mathrm{NaOH}$ molar ratio at 3,4 , 5,6 and $7 \mathrm{M}$. The resulting material characterization was done by using XRD, FTIR and SEM in order to characterize the geopolymer structures. Water absorption capacity was measured by immersing the geopolymer specimens in water for 24 hours. The results show that the optimum molar ratio of $\mathrm{NaOH}$ was $3 \mathrm{M}$, which water absorption capacity was $11.10 \%$ wt.
\end{abstract}

\section{Introduction}

Porous material of ceramic is a potential material to be used as an absorbent (water absorber)[1]. Water absorber is very useful, especially as a planting medium where the landmass area is limited. Porous ceramics prepared from clay minerals show high water adsorption capacity, high adsorption rate and slow water release rate due to their unique microporous structure [2]. Another new advantage of using porous ceramics is that such material is produced environmentally friendly without the need for combustion processes at high temperatures. Geopolymer is one of the best materials to prepare a porous ceramic material. Synthesis of geopolymer is generally carried out by reacting an alkali silicate solution with a solid aluminosilicate such as metakaolin, fly ash and so forth under alkaline conditions. Thokchom et al. (2009) state that the less alkali specimens the geopolymer contains, the higher porosity and water absorption the geopolymer possess. In this study, geopolymer was synthesized by using fly ash as a base material and alkaline solution and sodium silicate as additional materials. The synthesis was carried out at temperature of $25^{\circ} \mathrm{C}$ involving variations of $\mathrm{NaOH}$ molar ratio. The product was characterized by X-Ray Diffraction (XRD), Fourier Transform Infrared (FTIR) and Scanning Electron Microscopy (SEM). The measurement of maximum water absorption capacity was conducted by immersing the samples of geopolymer in distilled water for 24 hours.

\footnotetext{
* Corresponding author: aufafa.anggarini@uisi.ac.id
} 


\section{Experimental section}

\subsection{Material and instrumentation}

The materials used in this research were fly ash, the source of aluminium and silica, which is the waste from coal combustion at Steam Power Plant (PLTU) Paiton, Na2SiO3, NaOH pellet $(99 \%$, Merck) as alkali activator, distilled water and $\mathrm{KCl}$. The analysis X-ray Diffraction (XRD) was conducted to identify the chrystal phase of geopolymer by using $\mathrm{Cu}-\mathrm{K} \alpha$ radiation. FTIR spectrum of geopolymer samples were analyzed to determine the presence of $\mathrm{KCl}$ inside geopolymer matrix. Scanning Electron Microscope (SEM) images were analyzed to identify the morphology of geopolymer. The water storage capacities of geopolymer samples were measured by immersing geopolimer matrix in distilled water for 24 hours at $25^{\circ} \mathrm{C}$.

\subsection{Procedure}

The fly ash refers to industrial waste collected from a power plant in Paiton, Indonesia which is used as aluminosilicate source. This material was prepared by shieving with sieve no. 325 and drying at $85^{\circ} \mathrm{C}$ for 24 hours. $\mathrm{NaOH}$ solution was prepared by dissolving $\mathrm{NaOH}$ pellet in distilled water, continued with 24 hours storage. Alkali solution was prepared by mixing sodium silicate and $\mathrm{NaOH}$ solution. In this research, the variations of $\mathrm{NaOH}$ molar ratio were 3, 4, 5, 6 and $7 \mathrm{M}$. Fly ash, as the starting material, was mixed with alkali solution, then $\mathrm{KCl}$ salt was added into geopolymer paste. This mixture was casted and cured at $85^{\circ} \mathrm{C}$ for 24 hours.

\subsection{The measurement of water storage capacity}

Geopolymer specimen was weighed and determined as initial weight (wo). These samples were then immersed in destilled water for 24 hours at $25^{\circ} \mathrm{C}$. The saturated dry surface was weighed as final weight (wf). Water absorption capacity was calculated and reported as increase in weight percentage.

\section{Result and discussion}

Geopolymer has been synthesized using fly ash and alkali solution. Abdullah, et al (2011) stated that geopolymer containing silica and alumina will react with alkali solution to produce chain and ring that contain three dimensional polymer. The existance of three dimensional ring in geopolymer can be used for water and nutrient storage for plantation aplication. Okada, et al (2009) stated that geopolymers are good candidates for water absorbers due to their microstructure.

\subsection{Effect of $\mathrm{KCl}$ content toward the structure of geopolymer}

In this research, the synthesis of geopolymer was followed by adding 3\% wt of $\mathrm{KCl}$ as plant nutrition. Potassium chloride is the most widely used potassium fertilizer because it contains more potassium than any other source do and this material has no significant pollution impact on water. The FTIR spectrum of geopolymer synthesized under varying $\mathrm{NaOH}$ molar ratio is shown in Figure 1. 


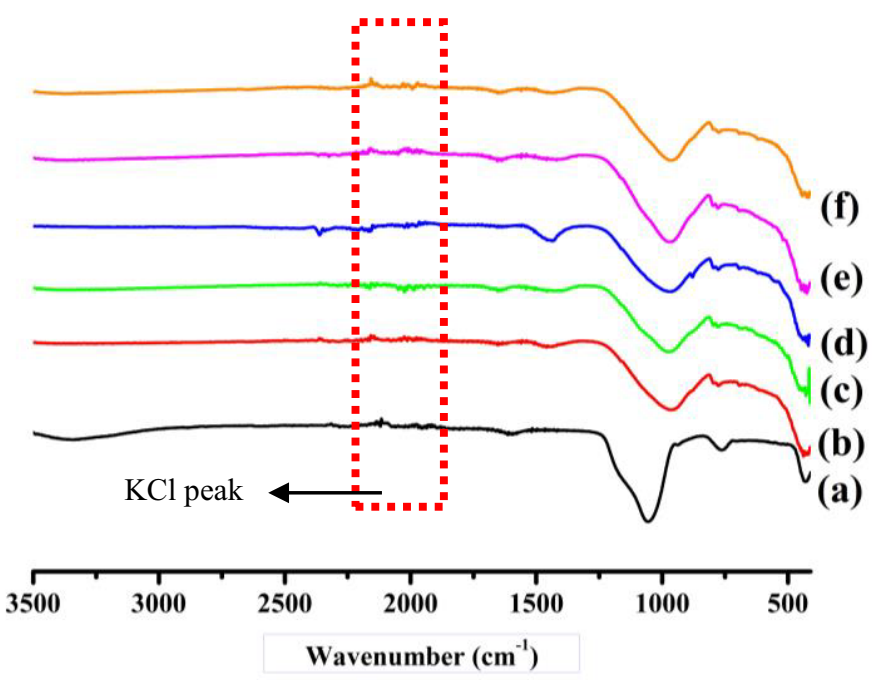

Fig. 1. FTIR spectrum of $\mathrm{KCl}$ (a), Geopolymer with $\mathrm{NaOH}$ molar ratio variation : $3 \mathrm{M}$ (b), $4 \mathrm{M}$ (c), $5 \mathrm{M}$ (d), $6 \mathrm{M}(\mathrm{e})$, and $7 \mathrm{M}(\mathrm{f})$

$\mathrm{KCl}$ sample was investigated by using FTIR and the result shows high peak at wavenumber of $1096 \mathrm{~cm}-1$. FTIR spectrum of all samples geopolymer shows the presence of $\mathrm{KCl}$ mineral and this result indicates that $\mathrm{KCl}$ does not react with geopolymer matrix and can be used for plant nutrition.

\subsection{Effect of $\mathrm{NaOH}$ molar ratio toward the structure of geopolymer}

The crystal phase of geopolymer samples were investigated by using XRD. Geopolymerization reaction can form phases, such as quartz, mullite, magnetite and sodalite. Figure 2 shows the XRD pattern of fly ash and geopolymer samples. The diffractogram of fly ash can be seen in Figure 2(a), while quartz was the phase most widely found at peak (20) of $26.72^{\circ}, 39.49^{\circ}$ and $50.49^{\circ}$. Another phase found in fly ash sample was mullite shown at peak $(2 \theta)$ of $16.48^{\circ}, 23.47^{\circ}, 31.15^{\circ}, 33.2^{\circ}, 35.29^{\circ}, 40.89^{\circ}, 42.55^{\circ}, 49.52^{\circ}, 53.66^{\circ}$ and $57.56^{\circ}$. The diffractogram of geopolymer samples synthesized from fly ash exhibits transformation from

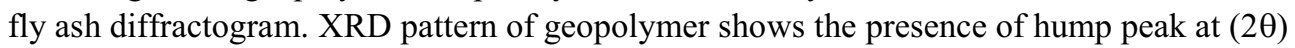
of $11^{\circ}-40^{\circ}$ indicating the formation of geopolymer phase which has been done. However, the quartz phase found in XRD pattern of geopolymer samples at $(2 \theta)$ of $27^{\circ}$ indicate the presence of unreacted fly ash. 


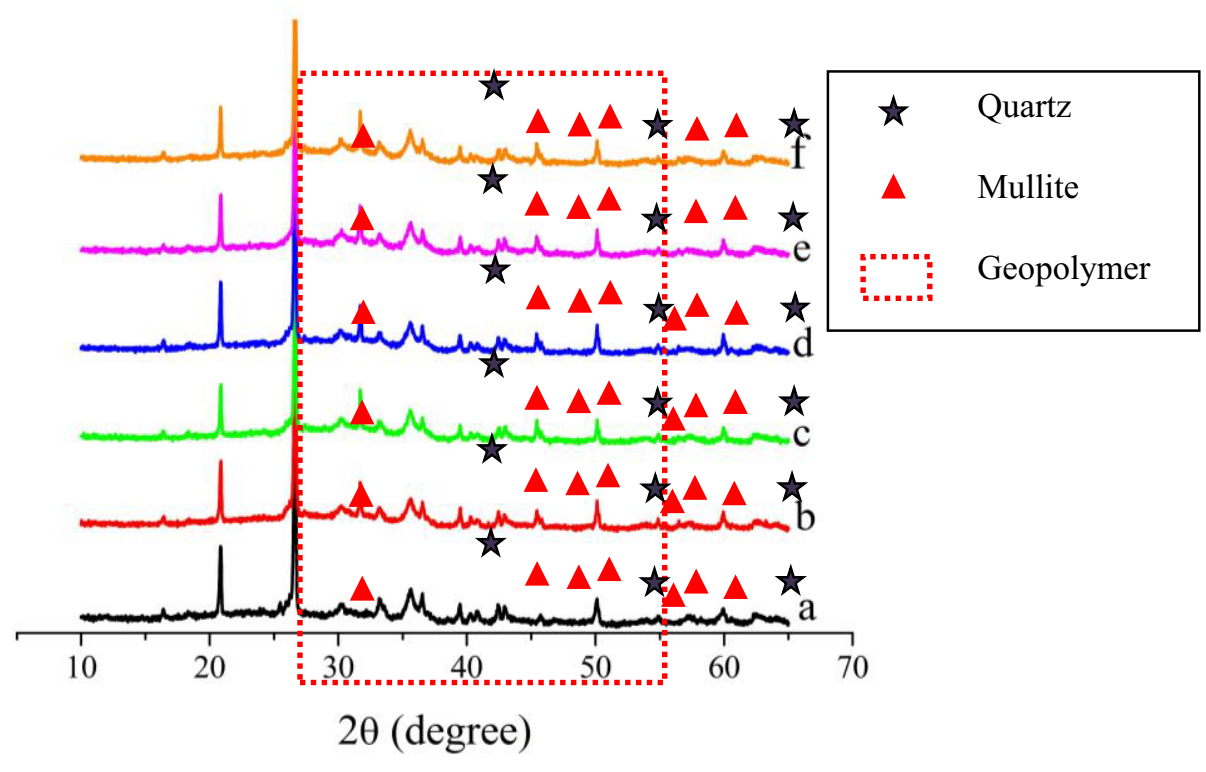

Fig. 2. The XRD pattern of (a) fly ash and geopolymer with $\mathrm{NaOH}$ molar ratio variation of (b) $3 \mathrm{M}$, (c) $4 \mathrm{M}$, (d) $5 \mathrm{M}$, (e) $6 \mathrm{M}$ and (f) $7 \mathrm{M}$

\subsection{The Effect of $\mathrm{NaOH}$ molar ratio toward the morphology of geopolymer}

The morphology of geopolymer samples was characterized by using SEM as seen in Figure 3. The particle size of geopolymer varied with the $\mathrm{NaOH}$ molar ratio. The particle size of geopolymer synthesized with $3 \mathrm{M} \mathrm{NaOH}$ solution is smaller than those synthesized with more concentrated $\mathrm{NaOH}$ solution. Hence, the higher $\mathrm{NaOH}$ molar ratio used to synthesize geopolymer, the bigger its particle size. Thokchom, et al (2009) stated that as the $\mathrm{NaOH}$ molar ratio increases, the reactivity of geopolymerization will also increase. As the particle size become smaller, geopolymer will certainly has higher surface area and more enhanced absorption capacity. Geopolymer with high porosity consists of agglomerated fine particles and less platy shape [1]. Geopolymer with $3 \mathrm{M} \mathrm{NaOH}$ produces fine particle agglomerate, as seen in Figure 3(a). This result is supported by water absorption capacity measurement data, which shows that geopolymer synthesized with $3 \mathrm{M} \mathrm{NaOH}$, the most dilute $\mathrm{NaOH}$ solution used, absorb more water than the others do.
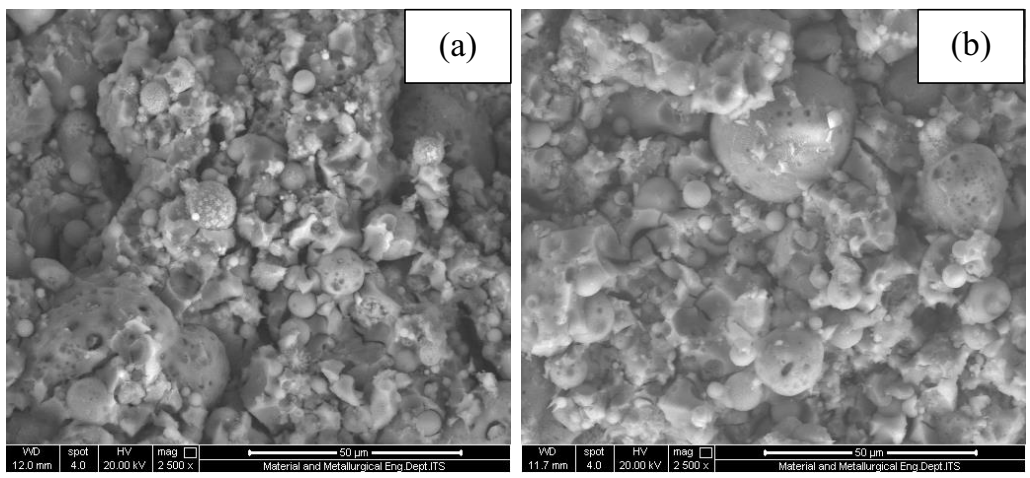

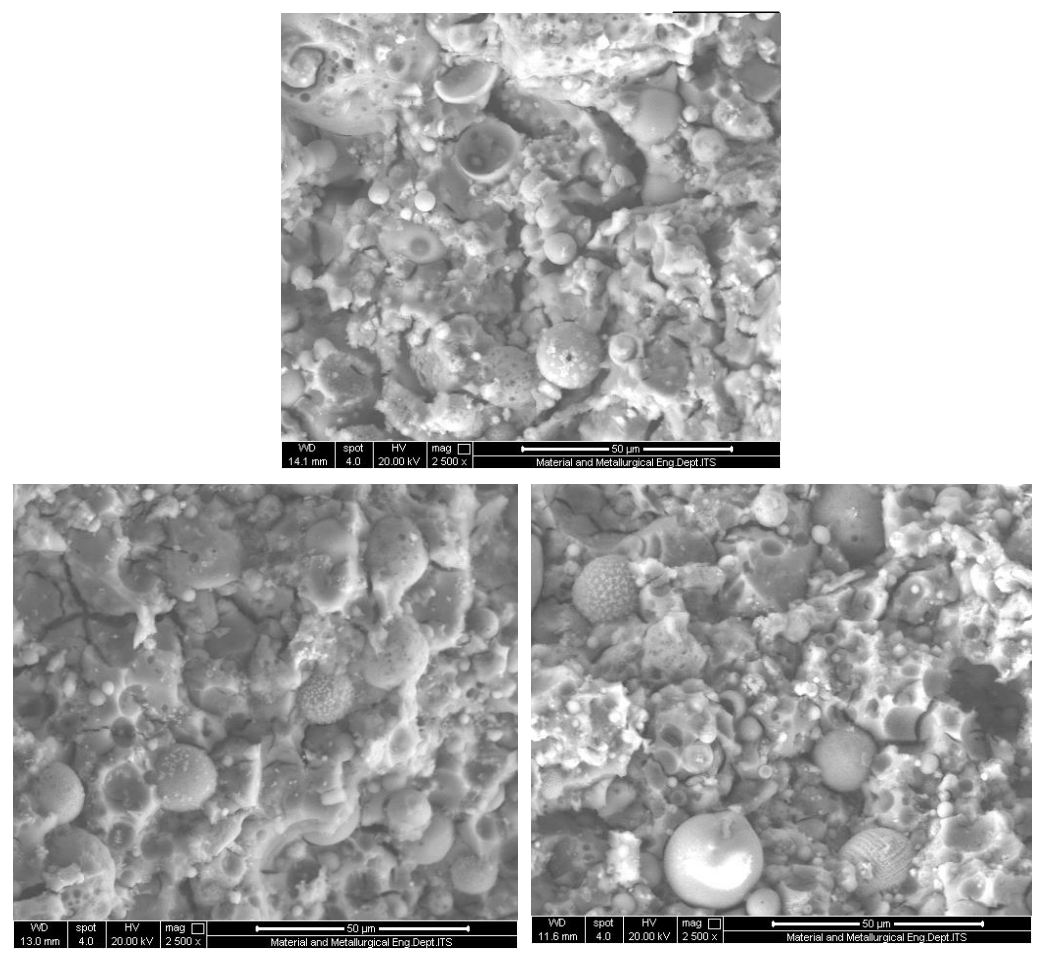

Fig. 3. SEM images of geopolymer samples with variation $\mathrm{NaOH}$ molar ratio of (a) $3 \mathrm{M}$, (b) $4 \mathrm{M}$, (c) $5 \mathrm{M}$, (d) $6 \mathrm{M}$ and (e) $7 \mathrm{M}$

\subsection{Water absorption capacity measurement}

Figure 4 indicates the corellation between $\mathrm{NaOH}$ molar ratio variation and water storage capacity of geopolymer samples. The results show that the activity of water storage material increases with the decrease of $\mathrm{NaOH}$ molar ratio. Thockhom, et al (2009) stated that $\mathrm{NaOH}$ used as catalyst in geopolymerization reaction will increase higher alkali content in the mix.

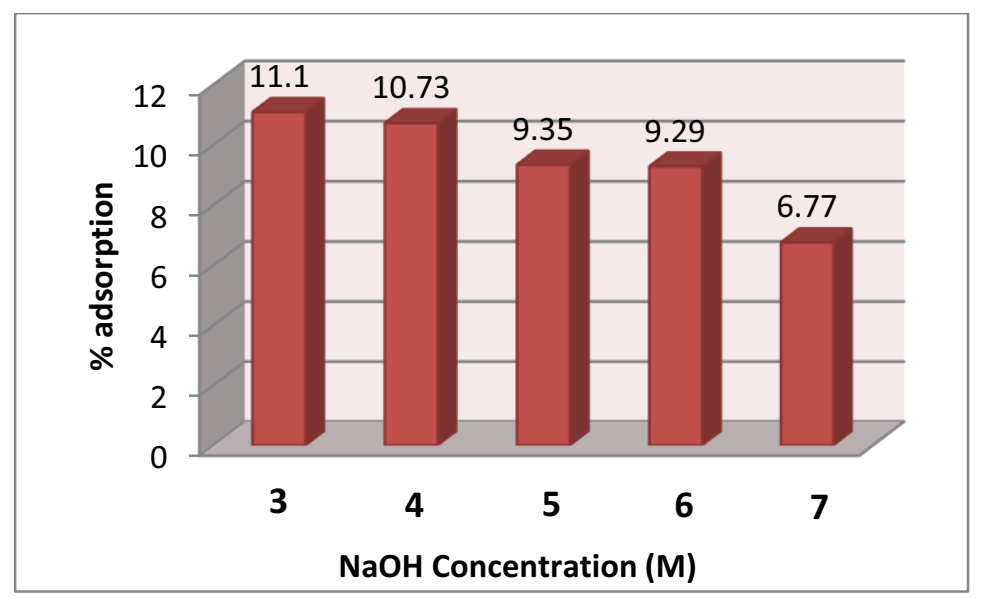

Fig. 4. Water absorption capacity of geopolymer samples with $\mathrm{NaOH}$ molar ratio variation 
Moreover, the reactivity of geopolymer will also increase as fly ash is used, so that denser microstructure of geopolymer will be accomplished. This result is appropriate with the XRD result showing that denser microstructure of geopolymer was achieved by using $\mathrm{NaOH}$ solution which molar ratio is higher. Geopolymer synthesized with $3 \mathrm{M} \mathrm{NaOH}$ produces a material with higher pore formation and allows more water molecules to penetrate the geopolymer specimen.

\section{Summary}

Geopolymer has been synthesized from fly ash as an aluminosilicate source with $\mathrm{NaOH}$ molar ratio variations of 3, 4, 5, 6 and $7 \mathrm{M}$. The XRD and SEM results show that the lower $\mathrm{NaOH}$ molar ratio, the higher microstructure pores and the lower particle size of geopolymer. Moreover, geopolymer specimen synthesized with lower $\mathrm{NaOH}$ molar ratio shows higher water storage capacity.

The authors wish to thank LPPM UISI for providing Hibah Riset Bersaing UISI, contract number 03/KP.01/10-01/02.16 date February 19th, 2016

\section{References}

1. K.Okada, A.Ooyama, T.Isobe, Y. Kameshima, A. Nakajima, K.J. MacKenzie, J. Eur. Ceram. Soc., 29, 1917 (2009)

2. K. Okada, S. Matsui, T. Isobe, Y. Kameshima, A. Nakajima, Journal of Ceram. Intern., 34, 345 (2008)

3. S. Thokchom, P. Ghosh, S. Ghosh, J. Eng. Appl. Sci. 4, 28 (2009)

4. M.M.A. Abdullah, K. Hussin, M. Bnhussain, K. N. Ismail, W.M.W. Ibrahim, Int. Journal of Pure and App. Sci and Technol., 6, 35 (2011)

5. U. Rattanasak, P. Chindaprasirt, Miner. Eng., 22, 1073 (2009)

6. J. Davidovits, J. Therm. Anal., 37, 1633 (1991)

7. Skvara, Frantisek, Kopecky, Lumboir, Nemecek, Jiri, Bittnar, Zdenek, Ceram.-Silikaty, 50, 208 (2006)

8. Xu, Hua, Deventer, S.J. Van, Ind. Eng. Chem. Res., 42, 1698 (2003)

9. Mishra, Anurag, Choudhary, Deepika, Jain, Namrata, Kumar, Manish, Sharda Nidhi, and Dutt, Durga, ARPN Journal of Engineering and Applied Sciences, 3, 14 (2008),

10. Xu, Hua, Deventer, S.J. Van, Ind. Eng. Chem. Res., 42, 1698 (2003) 